Letters to the Editor

\section{Listeria monocytogenes meningitis in previously healthy adults}

Sir,

We have read with interest the recent report by Drs C.J. Hearmon and S.K. Ghosh concerning Listeria monocytogenes meningitis in previously healthy adult patients, ${ }^{1}$ and we would like to add some comments on the diagnostic challenges that very often listeric meningitis present to clinicians.

Meningitis caused by $L$. monocytogenes may mimic either a viral, a tuberculous or even a partially-treated bacterial meningitis. ${ }^{1-4}$ The clinical differential diagnosis is often difficult because there are no pathognomonic stigmata and early available microbiological data are usually scarce. ${ }^{4}$ This may have important therapeutic implications, mainly when the diagnosis of tuberculous or partially-treated bacterial meningitis is entertained. However, there are some clues that may be useful in distinguishing meningitis caused by $L$. monocytogenes from tuberculous and partially-treated bacterial meningitis.

In the last 10 years we have cared for 14 adult patients ( 8 men and 6 women) with meningitis caused by $L$. monocytogenes. Only four patients $(28.5 \%)$ did not have any underlying disease predisposing them for acquiring listeric meningitis. Nine of the patients $(64.3 \%)$ presented with a subacute form of meningitis, and four (28.6\%) had focal neurological signs on admission to the hospital. Eleven patients $(78.6 \%)$ had hypoglucorrhachia, $13(92.8 \%)$ had hyperproteinorrhachia, and $13(92.8 \%)$ pleocytosis which was polymorphonuclear in 9 and lymphocytic in 4 patients. The Gram-stained smear of the cerebrospinal fluid (CSF) did not demonstrate organisms in any of the patients whereas the CSF culture was positive in all of them. We have compared the clinical findings, CSF data and peripheral blood data from these patients with those of 21 adult patients with a microbiologically proved tuberculous meningitis and with those of 30 adult patients with partially-treated bacterial meningitis. Results are summarized in Table I. Patients with tuberculous meningitis had a significantly lower level of glucose and chloride in the CSF than patients with $L$. monocytogenes and partially-treated bacterial meningitis. On the other hand patients with a partially-treated bacterial meningitis had a peripheral leucocyte count significantly higher than patients with listeric meningitis and these in turn had a significantly higher monocyte count in peripheral blood than patients with a partially-treated bacterial meningitis. Eighty four percent of the patients with tuberculous meningitis had a CSF chloride content equal or lower than $110 \mathrm{mmol} / \mathrm{l}$, compared with $10.5 \%$ of patients with listeric meningitis $(P=0.001)$ and $5.2 \%$ of patients with partiallytreated bacterial meningitis $(P=0.0001)$. The experimental sensitivity and specificity for a CSF chloride value lower than $110 \mathrm{mmol} / \mathrm{l}$ in order to differentiate tuberculous from other types of meningitis is $76.2 \%(P<0.05)$ and $93.2 \%(P<0.05)$ respectively, with estimated positive and negative predictive values of $84.2 \%$ and $89.1 \%$ respectively.

When early available microbiological data are absent, an aetiological diagnosis of a subacute lymphocytic meningitis can sometimes be very difficult. In this setting, the measurement of the CSF chloride content can be a useful guide to distinguish between listeric and tuberculous meningitis and eventually to institute an early adequate chemotherapy. On the other hand, the presence or absence of absolute

Table I Comparative CSF data and peripheral blood data from adult patients with listeric, tuberculous and partially-treated bacterial meningitis

\begin{tabular}{lccc}
\hline & LM meningitis & $M T$ meningitis & $P T B$ meningitis \\
\hline CSF glucose/serum glucose ratio* & $0.37 \pm 0.05$ & $0.22 \pm 0.02$ & $0.32 \pm 0.04$ \\
CSF protein $(\mathrm{g} / \mathrm{l}) \dagger$ & $2.6 \pm 0.5$ & $2.1 \pm 0.2$ & $3.8 \pm 0.6$ \\
CSF chloride (mmol/l) $\ddagger$ & $116 \pm 1.1$ & $105 \pm 1.9$ & $121 \pm 1.0$ \\
Peripheral WBC count (per litre)§ & $9987 \pm 1459$ & $8733 \pm 700$ & $14393 \pm 1529$ \\
$\begin{array}{l}\text { Absolute monocytosis in peripheral } \\
\text { blood }(>500 / 1) \text { (number of patients)\$ }\end{array}$ & $12(70.6 \%)$ & $9(69.2 \%)$ & $0(0 \%)$ \\
\hline
\end{tabular}

Values are expressed as mean \pm standard error of the mean.

$* P=0.005$ between LM and MT meningitis; $P=$ NS between LM and PTB meningitis; $P=0.04$ between MT and PTB meningitis.

$+P=$ NS between LM and MT meningitis; $P=$ NS between LM and PTB meningitis; $P=0.02$ between MT and PTB meningitis.

$\ddagger P=0.0002$ between $\mathrm{LM}$ and MT meningitis; $P=0.006$ between LM and PTB meningitis; $P=0.0001$ between MT and PTB meningitis.

$\S P=$ NS between LM and MT meningitis; $P=0.005$ between LM and PTB meningitis; $P=0.005$ between MT and PTB meningitis.

$\$ P=$ NS between LM and MT meningitis; $P=0.001$ between LM and PTB meningitis; $P=0.001$ between MT and PTB meningitis.

$\mathrm{CSF}=$ cerebrospinal fluid; $\mathrm{LM}=$ Listeria monocytogenes $; \mathrm{MT}=$ Mycobacterium tuberculosis; $\mathbf{P T B}=$ partiallytreated bacterial; $\mathrm{WBC}=$ white blood cell; NS $=$ not statistically significant. 
monocytosis together with the presence of neutrophilic leucocytosis in peripheral blood analyses can be of some value to differentiate both tuberculous and listeric meningitis from partially-treated bacterial meningitis.

\section{P. Domingo \\ J. Colomina \\ Department of Internal Medicine, Hospital de la Santa Creu i Sant Pau, Autonomous University of Barcelona,} Barcelona, Spain.

\section{References}

1. Hearmon, C.J. \& Ghosh, S.K. Listeria monocytogenes meningitis in previously healthy adults. Postgrad Med J 1989, 65: 74-78.

2. Bach, M.C. \& Davis, K.M. Listeria rhombencephalitis mimicking tuberculous meningitis. Rev Infect Dis 1987, 9: 130-133.

3. Klein, N.C., Damsker, B. \& Hirshman, S.Z. Mycobacterial meningitis. Retrospective analysis from 1970 to 1983. Am J Med 1985, 79: 29-34.

4. Domingo, P., Mancebo, J., Blanch, L.I., Coll, P., Net, A. \& Nolla, J. Meningitis por Listeria monocytogenes en adultos. Estudio de 10 casos. Rev Clin Esp 1986, 178: 158-163.

5. Griner, P.F., Mayewski, R.J., Mushlin, A.L. et al. Selection and interpretation of diagnostic tests and procedures. Ann Intern Med 1981, 94: 553-600.

\section{Is intestinal metaplasia a risk for gastric carcinoma?}

\section{Sir,}

Some authors believe that intestinal metaplasia, and in particular the type with incomplete cellular differentiation and secretion of sulphomucins, has a potential for malignancy in gastric carcinoma. ${ }^{1.2}$ This evaluation derives from having observed an association between this type of intestinal metaplasia and gastric carcinoma.

Other authors believe, on the contrary, that intestinal metaplasia has no significance in the screening for gastric carcinoma. ${ }^{3,4}$

Intestinal metaplasia of gastric mucosa would signify a reaction to stimuli of various types (for example chronic inflammation and regenerative processes) $)^{3.5}$ and, in the case of an association with carcinoma, of paraneoplastic phenomenon. In particular, Hattori believes that intestinal metaplasia, dysplasia and gastric carcinoma arise coincidentally. ${ }^{6}$ Such different conclusions are the result of the difficulties in carrying out accurate and prolonged followups.

We followed 223 patients who had gastric ulcers, studying the tissue repair. ${ }^{7}$ The average period of observation was 32.4 months for the men and $\mathbf{4 2 . 5}$ months for the women. In 112 patients (64 men and 48 women) we observed intestinal metaplasia. The intestinal metaplasia was classified accord- ing to Jass and Filipe in type I (complete), type IIA and type IIB (incomplete) in relation to the absence or presence in these last two types of sulphomucins in the columnar mucous cells. $^{8}$ In 1985 the types IIA and IIB were redefined as II and III respectively, confirming the importance of type III in the screening of gastric carcinoma. ${ }^{9}$ In 19 cases, that is $8.5 \%$ of the patients we considered, we observed metaplasia of type IIB or III.

In this study we noticed the appearance of gastric carcinoma and more precisely of early gastric cancer in only 2 $(0.9 \%)$ of the whole series of cases. Taking into account that the evolution of gastric ulcer into carcinoma is not more than $1 \%$ of the patients ${ }^{10}$ and referring to our data, we can say that intestinal metaplasia type IIB or III in the stomach does not appear to be a clear element of neoplastic risk.

$$
\begin{array}{r}
\text { Paolo Sossai } \\
\text { Roberto Cielo } \\
\text { Renzo Barbazza' } \\
\text { Gastroenterology Unit, Department of Medicine, } \\
\text { City Hospital, } 32032 \text { Feltre, Italy; } \\
\text { 'Department of Pathology, } \\
\text { City Hospital, 32100, } \\
\text { Belluno, Italy. }
\end{array}
$$

\section{References}

1. Sipponen, P., Seppala, K., Varis, K. et al. Intestinal metaplasia with colonic-type sulphomucins in the gastric mucosa; its association with gastric carcinoma. Acta Pathol Microbiol Scand [A] 1980, 88: 217-224.

2. Segura, D.I. \& Montero, C. Histochemical characterization of different types of intestinal metaplasia in gastric mucosa. Cancer 1983, 52: 498-503.

3. Ectors, N. \& Dixon, M.F. The prognostic value of sulphomucin positive intestinal metaplasia in the development of gastric cancer. Histopathology 1986, 10: 1271-1277.

4. Ramesar, K.C.R.B., Sanders, D.S.A. \& Hopwood, D. Limited value of type III intestinal metaplasia in predicting risk of gastric carcinoma. J Clin Pathol 1987, 40: 1287-1290.

5. Oohara, T., Tohma, H., Aono, G., Ukawa, S. \& Kondo, Y. Intestinal metaplasia of the regenerative epithelia in 549 gastric ulcers. Hum Pathol 1983, 14: 1066-1071.

6. Hattori, T. Development of adenocarcinomas in the stomach. Cancer 1986, 57: 1528-1534.

7. Sossai, P., Cielo, R. \& Barbazza, R. Intestinal metaplasia in gastric ulcer tissue repair. Endoscopy 1988, 20: 335.

8. Jass, J. \& Filipe, M.I. A variant of intestinal metaplasia associated with gastric carcinoma: a histochemical study. Histopathology 1979, 3: 191-199.

9. Filipe, M.I., Potet, F., Bogomoletz, W.V. et al. Incomplete sulphomucin-secreting intestinal metaplasia for gastric cancer. Preliminary data from a prospective study from three centres. Gut 1985, 26: 1319-1326.

10. Morson, B.C., Sobin, L.H., Grundmann, E., Johansen, A., Nagayo, T. \& Serck-Hanssen, A. Precancerous conditions and epithelial dysplasia in the stomach. J Clin Pathol 1980, 33: 711-721. 